\title{
A patient with metformin-associated lactic acidosis successfully treated with continuous renal replacement therapy: a case report
}

\author{
Hiroki Kinoshita ${ }^{1 *}$, Machi Yanai ${ }^{1}$, Koichi Ariyoshi ${ }^{1}$, Motozumi Ando ${ }^{2}$ and Ryo Tamura ${ }^{3}$
}

\begin{abstract}
Background: Metformin has been widely used as a first-line agent to treat type 2 diabetes mellitus. Lactic acidosis is a rare but serious adverse effect in patients treated with metformin. Recent studies noted a correlation between metformin accumulation and lactic acidosis. Continuous renal replacement therapy for the treatment of metforminassociated lactic acidosis has been documented in some case reports; however, there is currently no specific treatment for metformin-associated lactic acidosis.

Case presentation: A 70-year-old Japanese woman with type 2 diabetes mellitus presented to an emergency room with metformin-associated lactic acidosis. She was found to be hypotensive and laboratory examinations revealed severe lactic acidosis: pH 6.618, partial pressure of carbon dioxide in arterial blood $17.3 \mathrm{mmHg}$, bicarbonate $1.7 \mathrm{mmol} / \mathrm{L}$, and lactate $18 \mathrm{mmol} / \mathrm{L}$. Severe acidemia persisted despite supportive care including intravenously administered fluids, sodium bicarbonate, antibiotics, and vasopressors. Continuous renal replacement therapy was initiated in our intensive care unit. After dialysis for 3 days, her lactate level and pH value completely normalized. The concentration of metformin detected was $77.5 \mathrm{mg} / \mathrm{L}$, which is one of the highest in metformin-associated lactic acidosis successfully treated without overdose.

Conclusions: The present case had one of the highest metformin concentrations in metformin-associated lactic acidosis successfully treated with continuous renal replacement therapy, and serum metformin concentrations may be useful for the diagnosis of metformin-associated lactic acidosis. Metformin-associated lactic acidosis is a rare but important etiology of lactic acidosis. Continuous renal replacement therapy is advantageous for the treatment of hemodynamically unstable patients with metformin-associated lactic acidosis.
\end{abstract}

Keywords: MALA, Metformin, Lactic acidosis, CRRT, Continuous renal replacement therapy

\section{Background}

Metformin, a biguanide antihyperglycemic drug, has been widely used as a first-line agent to treat type 2 diabetes mellitus. It inhibits pyruvate carboxylase, which impairs the conversion of lactate to pyruvate, leading to impaired cellular respiration; this results in both lactate production and its impaired metabolism. Lactic acidosis is a rare but serious adverse effect in metformin-treated

\footnotetext{
* Correspondence: kinoshitahiroki1117@gmail.com

${ }^{1}$ Department of Emergency Medicine, Kobe City Medical Center General Hospital, 2-1-1, Minatojima-Minamimachi, Chuo-ku, Kobe, Hyogo 650-0047, Japan

Full list of author information is available at the end of the article
}

patients [1]. The incidence of metformin-associated lactic acidosis (MALA) is less than 1-9 cases/100,000 patient years [2]. The mortality rate is $30-50 \%$ [3]. Intermittent renal replacement therapy has been suggested as a treatment method for drug removal and the correction of severe acidemia; however, a standard treatment strategy has not yet been established [4]. Continuous renal replacement therapy (CRRT) and sustained low-efficacy dialysis (SLED) for the treatment of MALA have been documented in some case reports $[5,6]$. The advantages of CRRT and SLED are improved tolerability

(C) The Author(s). 2019 Open Access This article is distributed under the terms of the Creative Commons Attribution 4.0 International License (http://creativecommons.org/licenses/by/4.0/), which permits unrestricted use, distribution, and 
by hemodynamically unstable patients. We describe a case of MALA that was successfully treated with CRRT.

\section{Case presentation}

A 70-year-old Japanese woman with a history of type 2 diabetes mellitus presented to our emergency room with diarrhea, nausea, and vomiting for 3 days. She also had a history of colon polyps, depression, and chronic kidney disease (CKD) stage G3a. She had been taking metformin $1000 \mathrm{mg} /$ day for more than 3 years without changing the dosage. Her condition was normal until 3 days before her admission when she started to have repeated diarrhea and vomiting. Her consciousness was deteriorating on the day of her admission. Her vital signs on arrival were as follows: blood pressure $71 / 56 \mathrm{mmHg}$, heart rate 85 beats per minute, temperature $35.7^{\circ} \mathrm{C}$, oxygen saturation $86 \%$ on room air, and respiratory rate 24 breaths per minute with Glasgow Coma Scale E4V4M5. Her initial laboratory examination revealed severe kidney injury with blood urea nitrogen (BUN) of $67.5 \mathrm{mg} / \mathrm{dL}$ and creatinine of $10.17 \mathrm{mg} /$ $\mathrm{dL}$ and she had metabolic acidosis with a high lactate level: $\mathrm{pH}$ 6.618, partial pressure of carbon dioxide in arterial blood $\left(\mathrm{PaCO}_{2}\right) 17.3 \mathrm{mmHg}$, bicarbonate $\left(\mathrm{HCO}_{3}{ }^{-}\right) 1.7$ $\mathrm{mmol} / \mathrm{L}$, and lactate $18 \mathrm{mmol} / \mathrm{L}$ (Table 1). Whole-body computed tomography showed maxillary sinusitis and a uterine fibroid, but no evidence of infection.

Although supportive measures, including intravenously administered fluids, sodium bicarbonate, vasopressors, and antibiotics, were initiated, severe acidemia and

Table 1 Laboratory results on admission

\begin{tabular}{llllll}
\hline \multicolumn{3}{l}{ Biochemistry } & \multicolumn{2}{l}{ Complete blood count } & \multicolumn{2}{l}{ Blood gas } \\
\hline TP & $6.2 \mathrm{~g} / \mathrm{dL}$ & WBC & $17,800 / \mu \mathrm{L}$ & $\mathrm{pH}$ & 6.618 \\
Alb & $3.5 \mathrm{~g} / \mathrm{dL}$ & $\mathrm{Hb}$ & $9.7 \mathrm{~g} / \mathrm{dL}$ & $\mathrm{PaCO}_{2}$ & $17.3 \mathrm{mmHg}$ \\
$\mathrm{BUN}$ & $67.5 \mathrm{mg} / \mathrm{dL}$ & $\mathrm{Ht}$ & $35.7 \%$ & $\mathrm{PaO}_{2}$ & $71.1 \mathrm{mmHg}$ \\
$\mathrm{Cre}$ & $10.17 \mathrm{mg} / \mathrm{dL}$ & $\mathrm{Plt}$ & $27.6 \times 10^{4} / \mu \mathrm{L}$ & $\mathrm{HCO}_{3}{ }^{-}$ & $1.7 \mathrm{mmol} / \mathrm{L}$ \\
$\mathrm{Na}$ & $143 \mathrm{mEq} / \mathrm{L}$ & & & $\mathrm{AG}$ & $31.3 \mathrm{mmol} / \mathrm{L}$ \\
$\mathrm{K}$ & $5.4 \mathrm{mEq} / \mathrm{L}$ & & & & \\
Cl & $100 \mathrm{mEq} / \mathrm{L}$ & & & \\
Ca & $7.7 \mathrm{mg} / \mathrm{dL}$ & & & & \\
Glu & $99 \mathrm{mg} / \mathrm{dL}$ & Coagulation test & $18 \mathrm{mmol} / \mathrm{L}$ \\
T-Bill & $0.2 \mathrm{mg} / \mathrm{dL}$ & PT-INR & 1.13 & & \\
AST & $79 \mathrm{U} / \mathrm{L}$ & PT\% & $80.5 \%$ & & \\
ALT & $52 \mathrm{U} / \mathrm{L}$ & APTT & 13.9 seconds & & \\
LDH & $305 \mathrm{U} / \mathrm{L}$ & & & \\
CRP & $0.31 \mathrm{mg} / \mathrm{dL}$ & & & & \\
\hline AG & & & & \\
\hline
\end{tabular}

AG anion gap, Alb albumin, ALT alanine aminotransferase, APTT activated partial thromboplastin time, $A S T$ aspartate aminotransferase, $B U N$ blood urea nitrogen, $\mathrm{Cre}$ creatinine, CRP C-reactive protein, Glu glucose, $\mathrm{Hb}$ hemoglobin, $\mathrm{HCO}_{3}{ }^{-}$bicarbonate, $\mathrm{Ht}$ hematocrit, $\mathrm{LDH}$ lactate dehydrogenase, $\mathrm{PaCO}_{2}$ partial pressure of carbon dioxide in arterial blood, $\mathrm{PaO}_{2}$ partial pressure of oxygen in arterial blood, Plt platelets, $P T$ prothrombin time, $P T$-INR prothrombin timeinternational normalized ratio, $T$-Bill total bilirubin, $T P$ total protein, $W B C$ white blood cells hemodynamic instability persisted. Tracheal intubation was performed and she was transferred to the intensive care unit where she received urgent CRRT (continuous hemodiafiltration with a dialysate rate of $5000 \mathrm{~mL} /$ hour). Her lactate level and $\mathrm{pH}$ value completely normalized within 72 hours and, thus, CRRT and vasopressors were stopped (Fig. 1). She was extubated on day 6 and antibiotics were discontinued based on negative blood cultures on day 7. She left the intensive care unit on day 12 and was discharged on day 20. Her serum creatinine level before discharge was $1.11 \mathrm{mg} / \mathrm{dL}$.

After discharge, she was treated as an out-patient with orally administered anti-diabetic drugs other than metformin and her serum creatinine level remained stable. Her metformin level before CRRT was $77.5 \mathrm{mg} / \mathrm{L}$ (therapeutic range $0.5-2 \mathrm{mg} / \mathrm{L}$ ). Metformin concentrations were measured by high-performance liquid chromatographytandem mass spectrometry using an Agilent 1260 Infinity HPLC system (Agilent Technologies, Santa Clara, CA, USA) with an InertSustainSwift ${ }^{\text {tw }}$ C18 column $(2.1 \times 50$ $\mathrm{mm}, 2.0 \mu \mathrm{m}$; GL Sciences Inc., Tokyo, Japan) and QTRAP 4500 mass spectrometer (AB Sciex, Framingham, MA, USA) using isocratic elution of $10 \mathrm{mM}$ ammonium acetate and acetonitrile at a ratio of $80: 20(\mathrm{v} / \mathrm{v})$. The linearity of the calibration curve was between 6.25 and $100 \mathrm{mg} / \mathrm{L}$ with a determination coefficient of 0.999 .

\section{Discussion and conclusions}

We identified two important clinical issues. The present case had one of the highest metformin concentrations in MALA successfully treated with CRRT and serum metformin concentrations may be useful for the diagnosis of this condition. CRRT is an effective treatment for patients with MALA with hemodynamic instability.

Metformin blood concentrations ranging between 0.5 and $2.0 \mathrm{mg} / \mathrm{L}$ are within the therapeutic range, whereas those higher than $4.0 \mathrm{mg} / \mathrm{L}$ are generally considered to be toxic [1]. The causal link between metformin accumulation and lactic acidosis has been questioned [7, 8]. Previous studies reported a poor correlation, which may have reflected the suboptimal timing of sample collection [8]. Recent studies noted a correlation between metformin accumulation and lactic acidosis [9]. In the present case, the serum metformin level before CRRT was $77.5 \mathrm{mg} / \mathrm{L}$. This level exceeded the lethal range of metformin concentrations $(>50 \mathrm{mg} / \mathrm{L})[6,10]$. Moreover, this patient had most of the poor prognostic indicators in MALA, such as advanced age, arterial $\mathrm{pH}$ less than 7.35, the need for mechanical ventilation, and vasopressors [11]. Although a poor prognosis was expected, we successfully treated one of the highest metformin concentrations in MALA with CRRT. Our suspicion of MALA was supported by the high level of metformin. Although plasma metformin concentrations are not easily available in all laboratories, it is important to 


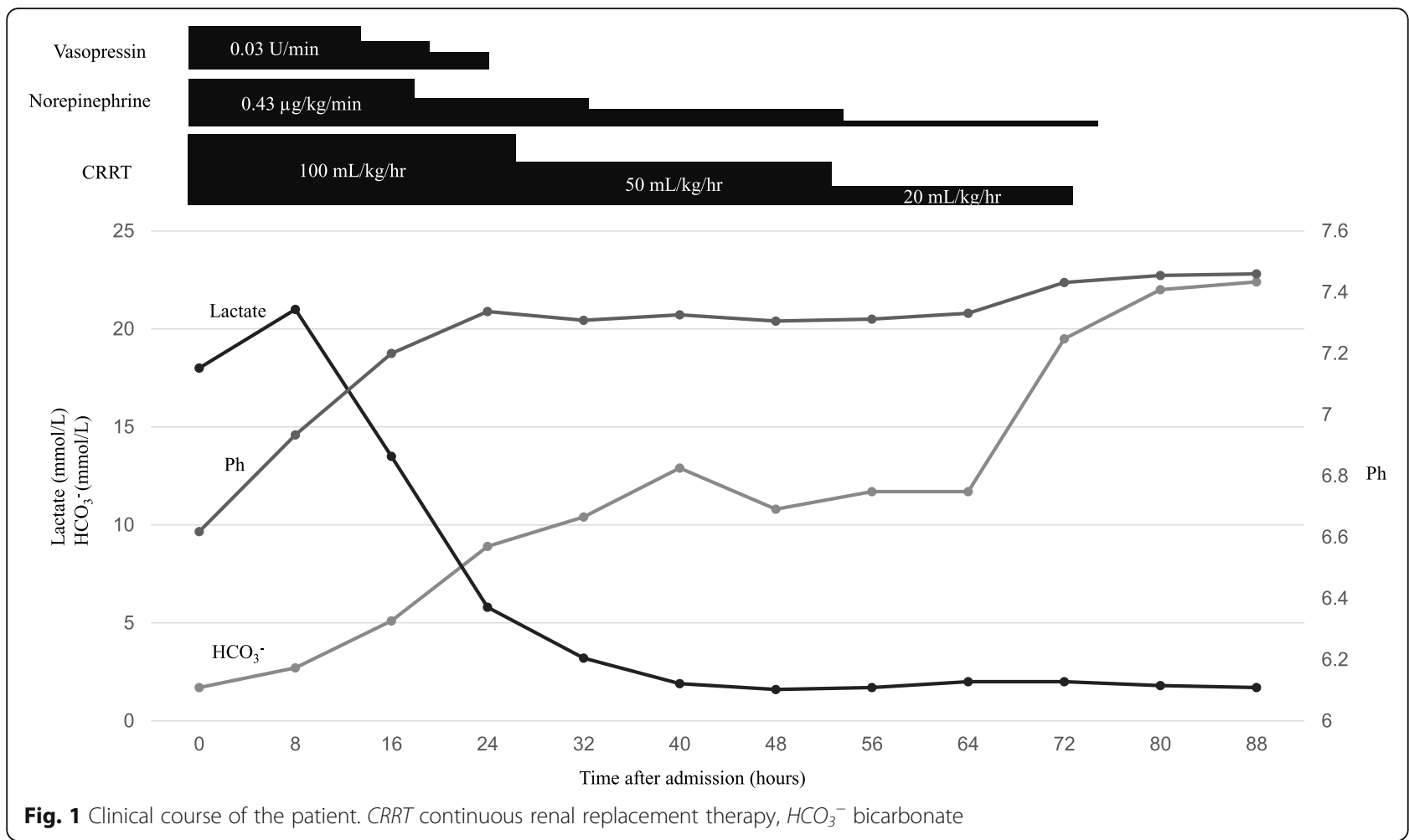

ensure specimen storage because plasma metformin concentrations measured in the emergency room will contribute to an accurate diagnosis [12].

CRRT is an effective treatment for patients with MALA with hemodynamic instability. Initial therapy for MALA is resuscitation and supportive care. There is no specific treatment for MALA and sodium bicarbonate alone is generally not sufficient to correct acidosis. Metformin has a low molecular weight and its protein binding rate is limited; therefore, it freely diffuses through hemodialyzers and hemofilters [4]. Intermittent hemodialysis has been suggested as a treatment for drug removal and the correction of severe acidemia. CRRT for the treatment of MALA has been documented in some case reports [13]. The clearance of metformin may exceed $200 \mathrm{~mL} /$ minute with intermittent dialysis and up to $50 \mathrm{~mL} /$ minute with CRRT $[5,14]$. The clearance of drugs by CRRT may be less effective than that for intermittent hemodialysis, but needs to be considered for patients who are hemodynamically unstable. In our patient, intermittent dialysis was difficult because she was hemodynamically unstable to receive high doses of vasopressors. After CRRT was initiated, her lactate level and $\mathrm{pH}$ value improved and she subsequently recovered from shock. CRRT is an effective treatment for MALA if intermittent hemodialysis cannot be performed due to hemodynamic instability.

The most common symptoms of MALA are those related to the gastrointestinal tract (including nausea, vomiting, and diarrhea) followed by an altered mental status, shortness of breath, hypothermia, and hypotension [1]. Metformin toxicity may mimic sepsis with gastrointestinal symptoms. MALA is characterized by a blood lactate concentration greater than $5 \mathrm{mmol} / \mathrm{L}$ and arterial $\mathrm{pH}$ less than 7.35 in association with metformin exposure. Metformin clearance decreases with reductions in the glomerular filtration rate because metformin has limited metabolism and is mostly eliminated unchanged by the kidney [15]. In the present case, her serum metformin concentration was elevated because of prerenal acute renal failure induced by repeated diarrhea and vomiting. It was not clear whether repeated vomiting and diarrhea were due to enteritis or MALA; however, the present case demonstrated that MALA may occur even if patients take an appropriate amount of metformin. In emergency settings, difficulties may be associated with obtaining a detailed medical history; therefore, it is important to suspect MALA in patients with metabolic acidosis and elevated lactate levels in any setting. In the present case, we obtained a detailed medical history, which included a history of type 2 diabetes mellitus, treatment with metformin, and a history of preceding gastrointestinal symptoms; therefore, we immediately suspected MALA.

We described one of the highest metformin concentrations in MALA successfully treated with CRRT. Since MALA is difficult to differentiate from sepsis, particularly in severe cases, serum metformin concentrations may be useful for reaching a diagnosis. MALA needs to 
be considered a differential diagnosis in patients with type 2 diabetes mellitus receiving metformin even without overdose who have severe lactic acidosis. Although intermittent hemodialysis is the preferred approach, CRRT is an effective alternative for hemodynamically unstable patients.

\section{Abbreviations}

CRRT: Continuous renal replacement therapy; MALA: Metformin-associated lactic acidosis; SLED: Sustained low-efficacy dialysis

\section{Acknowledgements}

Not applicable.

\section{Authors' contributions}

HK conceived the study and drafted the manuscript. MY and KA participated in drafting the manuscript. MA and RT carried out data collection and the data analysis. All authors read and approved the final manuscript.

\section{Funding}

None.

\section{Availability of data and materials}

Not applicable.

Ethics approval and consent to participate

Not applicable.

\section{Consent for publication}

Written informed consent was obtained from the patient for publication of this case report and any accompanying images. A copy of the written consent is available for review by the Editor-in-Chief of this journal.

\section{Competing interests}

The authors declare that they have no competing interests.

\section{Author details}

${ }^{1}$ Department of Emergency Medicine, Kobe City Medical Center General Hospital, 2-1-1, Minatojima-Minamimachi, Chuo-ku, Kobe, Hyogo 650-0047, Japan. ${ }^{2}$ Division of Clinical Pharmacy, Faculty of Pharmaceutical Sciences, Kobe Gakuin University, Kobe, Japan. ${ }^{3}$ Department of Pharmacy, Kobe City Medical Center General Hospital, Kobe, Japan.

Received: 19 September 2019 Accepted: 13 November 2019

Published online: 17 December 2019

\section{References}

1. Vecchio S, Giampreti A, Petrolini VM, Lonati D, Protti A, Papa P, et al. Metformin accumulation: lactic acidosis and high plasmatic metformin levels in a retrospective case series of 66 patients on chronic therapy. Clin Toxicol (Phila). 2014;52:129-35.

2. Eppenga WL, Lalmohamed A, Geerts AF, Derijks HJ, Wensing M, Egberts A, et al. Risk of lactic acidosis or elevated lactate concentrations in metformin users with renal impairment: a population-based cohort study. Diabetes Care. 2014;37:2218-24.

3. Kajbaf F, Lalau JD. The prognostic value of blood pH and lactate and metformin concentrations in severe metformin-associated lactic acidosis. BMC Pharmacol Toxicol. 2013;14:22.

4. Calello DP, Liu KD, Wiegand TJ, Roberts DM, Lavergne V, Gosselin S, et al. Extracorporeal Treatment for Metformin Poisoning: Systematic Review and Recommendations From the Extracorporeal Treatments in Poisoning Workgroup. Crit Care Med. 2015;43:1716-30.

5. Dichtwald S, Weinbroum AA, Sorkine P, Ekstein MP, Dahan E. Metforminassociated lactic acidosis following acute kidney injury. Efficacious treatment with continuous renal replacement therapy. Diabet Med. 2012;29:245-50.

6. Greco P, Regolisti G, Maggiore U, Ferioli E, Fani F, Locatelli C, et al. Sustained low-efficiency dialysis for metformin-associated lactic acidosis in patients with acute kidney injury. J Nephrol. 2019;32(2):297-306.
7. Salpeter SR, Greyber E, Pasternak GA, Salpeter EE. Risk of fatal and nonfatal lactic acidosis with metformin use in type 2 diabetes mellitus. Cochrane Database Syst Rev. 2010:CD002967. https://doi.org/10.1002/14651858.CD002967.pub3.

8. Lalau JD, Lacroix C, Compagnon P, de Cagny B, Rigaud JP, Bleichner G, et al. Role of metformin accumulation in metformin-associated lactic acidosis. Diabetes Care. 1995;18:779-84.

9. Duong JK, Furlong TJ, Roberts DM, Graham GG, Greenfield JR, Williams KM, et al. The Role of Metformin in Metformin-Associated Lactic Acidosis (MALA): Case Series and Formulation of a Model of Pathogenesis. Drug Saf. 2013;36:733-46.

10. Acquistapace G, Rossi M, Garbi M, Cosci P, Canetta C, Manelli A, et al. Acute metformin intoxication: 2012 experience of Emergency Departement of Lodi, Italy. Clin Chem Lab Med. 2014;52:1489-97.

11. Seidowsky A, Nseir S, Houdret N, Fourrier F. Metformin-associated lactic acidosis: a prognostic and therapeutic study. Crit Care Med. 2009;37(7):2191-6.

12. Boucaud-Maitre D, Ropers J, Porokhov B, Altman JJ, Bouhanick B, Doucet J, et al. Lactic acidosis: relationship between metformin levels, lactate concentration and mortality. Diabet Med. 2016;33:1536-43.

13. Keller G, Cour M, Hernu R, Illinger J, Robert D, Argaud L. Management of metformin-associated lactic acidosis by continuous renal replacement therapy. PLoS One. 2011;6:e23200.

14. Barrueto F, Meggs WJ, Barchman MJ. Clearance of metformin by hemofiltration in overdose. J Toxicol Clin Toxicol. 2002;40:177-80.

15. Scheen AJ. Clinical pharmacokinetics of metformin. Clin Pharmacokinet. 1996;30(5):359-71.

\section{Publisher's Note}

Springer Nature remains neutral with regard to jurisdictional claims in published maps and institutional affiliations.

\section{Ready to submit your research? Choose BMC and benefit from:}

- fast, convenient online submission

- thorough peer review by experienced researchers in your field

- rapid publication on acceptance

- support for research data, including large and complex data types

- gold Open Access which fosters wider collaboration and increased citations

- maximum visibility for your research: over $100 \mathrm{M}$ website views per year

At BMC, research is always in progress.

Learn more biomedcentral.com/submissions 